SIR,-Mr. C. K. Vartan (26 June, p. 767) implies that those aspiring gynaecologists who are not prepared to be liberal abortionists should forget about the M.R.C.O.G. and train for some other branch of medicine. Surely this view will be vigorously challenged by individuals and by the Royal College of Obstetricians and Gynaecologists itself.

Those of us who terminate pregnancies at fairly regular intervals in accordance with what we believe to be the intention of the new Act, but for good reasons and not merely on demand, do not, I think, suffer from the distaste for the operation which Mr. Vartan and others like him say they feel.

This operation, like any other, is perfectly satisfactory when it is done for a proper reason. Mr. Vartan says that no one "enjoys this work." Surgeons do not "enjoy" amputating limbs, but they do not complain about having to do it when the reasons are good. Perhaps the gynaecologist who "is already doing more than he likes" should consider the possibility that his dislike stems from the unnecessary quality of some of his operations and the opprobrium of his nurses and his resident staff.

Mr. Vartan is a senior and respected member of our specialty and of the Royal College of Obstetricians and Gynaecologists. If he were not, his expressed opinion would be merely controversial. As it is, however, it must be firmly opposed at this stage for it is a very pernicious and completely new departure. Let those who wish to become gynaecologists be free from this outrageous sanction and let those who wish to become abortionists proceed along separate paths.-I am, etc., Banbury,

J. M. Gate

\section{Haemorrhage Mimicking Intravascular} Haemolysis

SIR.-We were interested to read the letter of Dr. Jeanne D. Reeve (12 June, p. 654) on haemorrhage mimicking intravascular haemolysis. We had a similar case recently that caused considerable diagnostic difficulty since we did not recognize the poscibility of an intra-abdominal haemorrhage simulating an episode of acute intravascular haemolysis. A brief description is given as we feel that this syndrome merits wider recognition

The patient was a 31-year-old negro woman, who presented with lower abdominal pain for three days. She was three months pregnant and was admitted for observation with a tentative diagnosis of an ectopic pregnancy. She was observed for one week during which time she had some further abdominal pain, started to pass small amounts of blood per vaginam, and was noted to have a haemoglobin of $6.4 \mathrm{~g} / 100 \mathrm{ml}$ She was transfused with two pints of blood and a D. and C. was performed since she was then considered to have a missed abortion. Nine hours postoperatively she collapsed pulseless with no recordable blood pressure, but recovered following the administration of intravenous Rheomacrodex, three pints $(1.7$ 1.) of blood, and hydrocortisone. Postoperative vaginal bleeding was minimal and no explanation for this collapse was found at that time. Two days postoperatively she started to pass dark red urine and six days postoperatively was transferred to Guy's for investigation.

On admission she did not appear obviously ill but still complained of intermittent lower abdominal pain, worse on micturition, and was noted to be mildly icteric. Investigation showed a haemoglobin of $8.7 \mathrm{~g} / 100 \mathrm{ml}$, with a reticulocytosis of $20 \%$. Total bilirubin was $4.5 \mathrm{~g} / 100$ $\mathrm{ml}$ and direct-reacting $1.5 \mathrm{mg} / 100 \mathrm{ml}$. Plasma haptoglobins were absent and methaemalbuminaemia present. The urine contained free haemoglobin, haemosiderin, and excess urobilinogen. A sternal bone marrow aspirate showed marked erythropoietic hyperplasia. It was thought that she had had an episode of acute intravascular haemolysis but this could not be explained. There was no evidence for a mismatched transfusion; Coombs test, Ham's test, and Donath$L=n d s t$ in $r$ antibociy $w r_{\text {_ }}$ all ncgative; blood cultures grew no organism, malarial parasites were not found; haemoglobin studies were normal. Other negative and normal tests included: examination of faeces for occult blood, liver function tests, plasma urea and electrolytes, plasma proteins, and chest $x$-ray. A midstream specimen of urine contained 30 leucocytes $/ \mathrm{mm}^{3}$, but no bacterial growth.

Within a few days her haemoglobinuria cleared complctely. Her haemoglobin rose gradually during the next two weeks to $9.8 \mathrm{~g} / 100 \mathrm{ml}$ and the reticulocyte count dropped to $7.5 \%$. Thirty days after her first admission she again developed acute pain in the left iliac fossa with tenderness and signs of peritoneal irritation. At laparotomy there was much old blood in the pelvis and an abdominal pregnancy with the placenta attached to the fimbrial end of the left fallopian tube. Postoperatively she made a rapid recovery and six weeks later had a normal haemoglobin, $14.4 \mathrm{~g} / 100 \mathrm{ml}$, with no evidence of haemolysis.

In retrospect it seems likely that the characteristics of an acute intravascular haemolytic episode were due to the intraabdominal haemorrhage, which presumably caused the episode of acute collapse and the anaemia and reticulocytosis. The absence of haptoglobins, the presence of methaemalbuminaemia, and the urinary features were due to reabsorption of haem pigments from the peritoneum. We were unaware of this syndrome until we read the letter of Dr. Reeve and hope that this report will help to emphasize it.-We are, etc.

P. J. BLACK

M. S. Rose

P. BARKHAN

Department of Haematology and Medicine, C. JOINER Guy's Hospital,

\section{Familial Hyperparathyroidism}

SIR,-In their paper on familial hyperparathyroidism (10 July, p. 87) Dr. P. Marsden and colleagues agree that this condition probably represents a form of the syndrome of multiple endocrine adenomatosis. Many patients with this syndrome have a gastrinproducing tumour and the highest association is with parathyroid tumours. ${ }^{1}$ Surely an indication existed here to perform gastric secretory studies on these patients together with immunoassays for circulating gastrin, as reliance on clinical and radiological findings for the diagnosis of a Zollinger-Ellison state is likely to be fallacious?

Likewise, an opportunity was not taken to assess the effect on gastric secretion of changing levels of serum calcium before and after parathyroidectomy. ${ }^{2}$-I am, etc.,

WaiKato Hospital

GraEME D. KeRR

Hamilton

\section{New Zealand}

1 Ballard, H. S., Frame, B., and Hartsock, R. J. 2 Medicine, 1964, 43, 481. 3 Kerr, G. D., and Smith, R., Lancet, 1967, 1,
Complications of B.C.G. Vaccination

SIR,-The interesting article by Dr. Sylvia M. Watkins on "Unusual Complications of B.C.G. Vaccination" (20 February, p. 442) includes a list of many complications of this procedure. However, this list does not include the possibility of a generalized hypersensitivity reaction.

Some two years ago we reported the case of a 13-year-old boy who showed a hypersensitivity reaction, involving the skin, muscles, and joints. ${ }^{1}$

The clinical picture responded poorly to steroids, but disappeared after tuberculostatic treatment. At that time we were unable to find a similar case in the literature.-I am, etc.,

Hasharon Hosvital
Petah-Tiqva, Israel

I. MACHTEY Machtey, I., Bandmann, M., and Palant, A.,
Lancet, 1968, 1, 140.

\section{Acute Complete Inversion of the Bladder}

SIR,-Acute inversion of the bladder is very rare. Only two cases have been previously reported in children. ${ }^{1}$ As the conditions is so rare, it is difficult to draw similarities between cases or explain exactly why the bladder inverts through the urethra. In the case we report here, we can only suggest that coughing may possibly have had some effect in inducing the inversion.

The patient, from the Kafr El-Sheikh Governorate of Egypt, was a female child aged two and a half years. She presented a swelling in the vulva, continuous dribbling of urine, and a rectal prolapse. This condition, which had occurred eighteen hours before the child was brought for examination, started suddenly and the swelling gradually increased in size within two hours. The condition had been preceded by a mild cough for three days.

On examination the child was in good general health. No abnormality was detected on abdominal examination. A local swelling pyriform in shape and slightly smaller than a tennis hall was present in the vestibule. The swelling was covered by smooth mucous membrane, which was continuous with the skin of the vestibule. It was red and glistening all over except for a small area at the outermost part, where there was a blackish discolouration. Posteriorly, there was a pocket of about $1.5 \mathrm{~cm}$ depth. in which the two ureteric orifices were clearly visible and the efflux of urine was continuously occurring. The urethral orifice was not found. The swelling was not expansile and showed no impulse on coughing. It was soft, flechy in consistency, and irreducible. There seemed a great possibility that this swelling was the bladder. Examination also confirmed that complete rectal prolapse was present. The vaginal introitus was normal and the hymen intact.

Since the swelling was irreducible, exploration was derided unon. Through a middle line suprapubic incision the cave of Retzius was explored. No bladder was found in the pelvic cavity. A finger passed beneath the anterior pubic arch could reach to the bottom of the external mass. With one finger from the inside and another from the outside, the thickness of the bladder wall could be felt between the fingers. The peritoneal cavity was opened, the uterus and its adenexa were 
found to be normally situated. The swelling was returned to the pelvic cavity with great difficulty, by continuous traction from inside and pushing from outside. After reduction of the swelling and opening of its anterior surface, the ureteric orifices were visible and urine was seen collecting in the opened lumen. It was thus confirmed that the prolapsed mass was a complete bladder.

The urethra could easily admit two fingers, clearly an unusual condition in a child of two and a half years. A strip of the urethra was excised longitudinally and the urethra was secured over a 14 French gauge rubber catheter. The bladder was closed completely in two layers and fixed to the anterior abdominal wall by two stitches. A drain was put in the cave of Retzius and the abdominal wall was closed. The urethral catheter was left indwelling for 14 days, after which the patient was continent with perfect control except for very slight stress incontinence.

Five groups of urinary bladder inversion are recognized: (1) inversion of a diverticulum; (2) inversion of only the bladder mucosa; (3) partial inversion of all layers of bladder wall; (4) total inversion of the whole viscus; and (5) inversion through a vesicovaginal fistula. Inversion occurs through the urethra in the first four groups. Sutherland and $\mathrm{Merki}^{2}$ point out the difficulty of replacing the bladder through the urethral sphincter. In their case of acute inversion during labour, as in others, the sphincter was ruptured during replacement. In the present case, the swelling was reduced without apparent damage to the sphincter. Probably the lapse of 18 hours between the onset of the condition and its treatment allowed time for some relaxation of the sphincter and thus the bladder could be returned to the pelvic cavity without rupture of the sphincter.-We are, etc.,

S. El-Hammady M. GHONEIM

Department of Urology,

Faculty of Medicine,

El-Man
Egypt

1 Campbell, M. F., (ed.) Urology, Vol. 3, p. 2048 Philadelphia, Saunders, 1963

Sutherland, J. C., and Merki, R. T., British Medical fournal, 1964, 2, 991 .

\section{Air Embolism during Haemodialysis}

SIR,-The paper by Dr. M. K. Ward and others (10 July, p. 74) suggests that all cases of air embolism in patients on haemodialysis occurred with infusion sites placed proximal to the blood pump. In the event of any leakage, air is bound to be sucked into the circuit. Perhaps the authors do not realize that this problem can be overcome with great ease. In this unit we place an R.85 insert (Avon Medicals) for heparin infusion immediately after the blood pump and before the dialyser. In this position there is always a positive pressure within the line and any potential leakage would be from inside to out. Any other infusions are given direct into the bubble trap, another high pressure area in the circuit. This necessitates the use of a high drip stand, but presents no other problems and is somewhat cheaper than the $£ 8,000$ for plastic bags quioted.-We are, etc.,

J. GRAINGER A. EISINGER

Dialysis Unit, Lodge Moor Hospital,

\section{Sterilization of Young Wives}

SIR,-Permit me to join Dr. R. J. Houseman (17 July, p. 184) when he asks that the nature of tubal ligation should be explained to both the husband and wife, but may I further suggest that this golden rule should also apply to the male sterilization operation-and that this explanation should be offered by both the surgeon concerned and the family doctor.

It is my belief that the family doctor has the key role in any sterilization decision. His knowledge of the physical and mental health of a husband and wife (and their children), and his awareness of their socio-

\section{Heparin in Acid Solutions}

SIR,-The Drug and Therapeutics Bulletin declared that heparin is "unstable in acid solutions (for example, dextrose)." Previously, dextrose solution had been considered the vehicle of choice for heparin infusion and although this statement has since been withdrawn ${ }^{2}$ it is evident that some uncertainty still exists.

We have conducted experiments designed

in duplicate. Up to at least 24 hours at room temperature $\left(23 \pm 2^{\circ} \mathrm{C}\right)$ there was never any indication of a loss. We have observed deterioration only after 60 hours at a minimum concentration of 1,000 units $/ \mathrm{ml}$. In normal hospital practice it is unlikely that heparin infusions would be kept for more than 24 hours. Typical results were as shown below.

\begin{tabular}{|c|c|c|c|c|c|c|}
\hline \multirow{3}{*}{$\begin{array}{c}\text { pH of } \\
\text { dextrose } \\
\text { solution }\end{array}$} & \multirow{3}{*}{$\begin{array}{c}\text { pH of } \\
\text { dextrose } \\
\text { after the } \\
\text { addition of } \\
\text { heparin pH 7.2 }\end{array}$} & \multirow{3}{*}{$\begin{array}{c}\text { Initial } \\
\text { mean } \\
\text { potency } \\
(\mathrm{u} / \mathrm{ml})\end{array}$} & \multicolumn{4}{|c|}{ mean potency at: (hours after preparation) } \\
\hline & & & \multicolumn{2}{|c|}{12} & \multicolumn{2}{|c|}{24} \\
\hline & & & $\mathbf{u} / \mathrm{ml}$ & $\%$ of initial & $\mathbf{u} / \mathbf{m l}$ & $\%$ of initial \\
\hline $4 \cdot 4$ & $7 \cdot 0$ & $\begin{array}{c}964 \\
(950-977) *\end{array}$ & $\begin{array}{c}970 \\
(961-980)\end{array}$ & 101 & 956 & 99 \\
\hline $4 \cdot 4$ & $6 \cdot 8$ & 200 & 197 & 99 & $\begin{array}{c}(94 /-904) \\
199\end{array}$ & 100 \\
\hline $4 \cdot 4$ & 6.6 & $\begin{array}{c}40 \\
(39-40)\end{array}$ & $\begin{array}{c}40 \\
(39-40)\end{array}$ & 100 & $\begin{array}{c}40 \\
(40-41)\end{array}$ & 100 \\
\hline
\end{tabular}

*fiducial limits of error.

to clarify the situation. Sterile heparin concentrates, 25,000 units $/ \mathrm{ml}$, were aseptically diluted with autoclaved $5 \%$ Dextrose Injection B.P. to arrive at a series of concentrations over the range in which heparin is likely to be infused clinically. At various times afterwards, potencies were determined

-We are, etc.,

London E.C.1

S. L. STOCK

N. WARNER Research Department

1 Drug and Therapeutics Bulletin, 1970, 8, 55. 2 Drue and Therapeutics Bulletin, 1971, 9, 24 British Pharmacopoeia, p. 1345. London, General
Medical Council, 1968.

\section{Infectiousness of Glandular Fever}

SIR,-In view of the supposed rarity of PaulBunnell positive glandular fever occurring within several members of a family, as recently pointed out by Dr. R. M. Whittington (26 June, p. 772), I would like to describe such an occurrence recently seen in general practice.

The initial case was in a girl, aged 10 presenting with earache, cervical adenitis, and a few yellow spots seen on a noninflamed left tonsil. She recovered completely within two weeks and returned to school. Her brother, aged 7, began to be ill two weeks later, complaining of a sore throat. On examination he had similar yellow spots on his tonsils, and also cervical lymphadenopathy. He remained quite ill for six weeks with generalized malaise and abnormal liver function tests. The third sibling, aged 10, presented eight weeks later with swellings on both sides of the neck, and she had been mildly off colour for the preceding two weeks. Blood tests were not carried out because this particular child is very sensitive, having severe eczema. The fourth sibling, a boy aged 8 , became ill a month later with a sore throat, enlarged cervical glands, necrotic looking tonsils, and a positive Hoagland's sign. Only in the last case was the spleen palpable.

The interval between the first and second case was 74 days, between the second and

In the most extensive field survey of glandular fever in general practice carried out by Hobson and Lawson in $1958^{1}$ all the Bunnell negative, as was also noted by Shubert and Collee in $1954^{2}$ in epidemics in close communities. Perhaps other practitioners have seen similar familial episodes and it may not really be so rare as indicated in the literature.-I am, etc.,

M. A. Casson

Manchester 20

1 Hobson, F. G., Lawson, B., and Wigfield, M.,

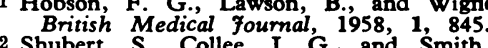
Shubert, S., Collee, J., G., and Smith, B. J.,

SIR,-I was interested in Dr. R. M. Whittington's (26 June, p. 772) experience with glandular fever. I have on two occasions observed an interval of six weeks third was 60 days, and between the third and fourth was 33 days. familial outbreak patients were always Paul- 